\title{
Private Health Insurance Incentives in Australia: The Effects of Recent Changes to Price Carrots and Income Sticks
}

\author{
Alex Robson ${ }^{\mathrm{a}}$ and Francesco Paolucci ${ }^{\mathrm{b}, \mathrm{c}}$ \\ ${ }^{a}$ Department of Accounting, Finance and Economics, Griffith University, QLD 4111, Australia. \\ Email: a.robson@griffith.edu.au \\ ${ }^{\mathrm{b}}$ Australian National University and Northumbria University, ACERH, The ANU, Building 62 Mills Road, \\ 2600 Acton, ACT, Australia. \\ E-mails: a.robson@griffith.edu.au; francesco.paolucci@anu.edu.au \\ ${ }^{\mathrm{c}}$ University of Northumbria, Coach Lane Campus, Benton, Newcastle Upon Tyne, NE7 7XA, UK.
}

Three major policy tools govern the demand for private health insurance (PHI) in Australia: premium-related subsidies (i.e. PHI-rebate); income tax surcharges (i.e. the Medicare Levy Surcharge (MLS)); and lifetime community-rating (i.e. Lifetime Health Cover). The first two provide a system of "carrots and sticks" to create incentives for increasing the demand for PHI. The third creates incentives for consumers to purchase PHI earlier than they otherwise would have, and to maintain this coverage over time even when prices rise. This paper makes a number of contributions to the existing literature. We develop a diagrammatic model that incorporates income heterogeneity and use it to consider two important policy issues: the effect of policy changes on consumer price responsiveness, and the effect of policy changes on the PHI take-up rates. The model suggests that recent changes to the income tax surcharge are likely to reduce the price elasticity of demand for insurance, which could have further consequences for outcomes in the PHI market and the health system more generally. Increases in premiums will reduce take-up, but could worsen the government's budget position, even if tax revenues were to rise. Finally, we conduct numerical simulations to examine the possible effects of recent policy changes, which are aimed at further means-testing the PHI rebate and the MLS. The simulation results suggest that these recently adopted policy changes are likely to reduce the take-up of PHI as well as consumers' responsiveness to future premium increases. The Geneva Papers (2012) 37, 725-744. doi:10.1057/gpp.2012.38

Keywords: private health insurance in Australia; regulation of health insurance markets; efficiency and affordability in health insurance markets; personal income taxation; premium and risk-related cross-subsidies; regulated competition

Article submitted 10 February 2012; accepted 26 July 2012; published October 2012

\section{Introduction}

The Australian health-care system features a public-private mix in health-care services financing and provision. Medicare is a universal tax-financed national health insurance scheme covering residents for the full costs of being treated as a public patient in a public hospital, and partly for medical and pharmaceutical costs. For private hospital charges, which are not covered by Medicare, individuals may 


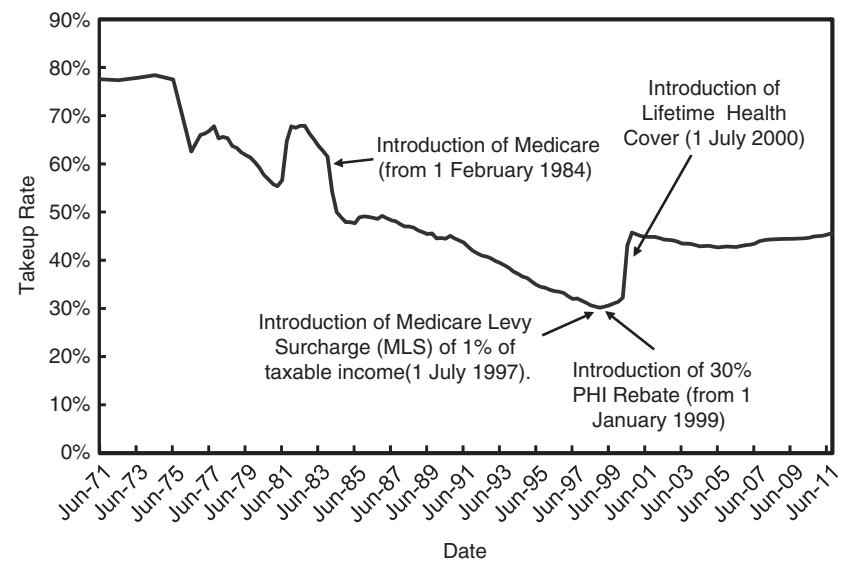

Figure 1. Private insurance (hospital treatment cover) in Australia-insured persons as a percentage of the population), 1971-2011.

Source: Private Health Insurance Administration Council ${ }^{1}$ from www.phiac.gov.au/for-industry/industrystatistics/statisticaltrends/.

voluntarily buy private health insurance (PHI) cover. In addition, PHI covers the costs of hospital services incurred by private patients in public hospitals (and other services already covered by Medicare) with increased choice of doctors and faster access than for non-PHI holders. Similar to most OECD countries, PHI serves also as supplementary coverage for services partly or wholly uncovered by Medicare, for example allied health-care services. $^{2}$

The public - private mix in health-care financing in Australia and the regulatory framework in the PHI market influence significantly the performance of PHI markets. For example, community rating and open enrolment regulations for PHI, which operate as legal restrictions to prevent risk-rating and selective underwriting by insurers, create incentives for (potentially significant) risk selection, which in the Australian context manifests itself mainly through the design of insurance products, for example premium differentiation via product differentiation. ${ }^{3}$

The impact of Medicare and other regulatory tools (in particular community-rating) on PHI demand can be seen in the steady decline in PHI membership numbers following Medicare's introduction in 1984 (from about 50 per cent to about 30 per cent in 1997, see Figure 1).

The dampening effect on the demand for regulatory and institutional arrangements has been somewhat offset by the three policy tools:

1. The Private Health Insurance Incentives (PHII) Act 1998 introduced the 30 per cent Private Health Insurance Rebate (PHIR). From April 2005, the rebate for persons

\footnotetext{
${ }^{1}$ Private Health Insurance Administration Council (2011).

${ }^{2}$ Paolucci (2011), OECD (2004).

${ }^{3}$ Butler (2002, 2007); Paolucci et al. (2006); Van de Ven and Schut (2007); Paolucci et al. (2011), Paolucci and Shmueli (2011).
} 
aged 65-69 years increased to 35 per cent and for persons aged 70 years and over it increased to 40 per cent.

2. The Medicare Levy Surcharge (MLS) (1997) is a tax penalty of 1 per cent of taxable income payable by single individuals with taxable incomes in excess of $\$ 70,000$ p.a. ${ }^{4}$ (\$140,000 p.a. for couples) if they do not hold PHI.

3. Lifetime Health Cover (LHC) introduced in July 2000 consists of an age penalty (i.e. yearly premium increase of 2 per cent) being imposed on individuals who first purchased PHI after age 30 years. Therefore, by enrolling "early" and by maintaining membership, individuals pay lower premiums throughout their lifetime relative to people who delay purchasing PHI for hospital cover.

While collectively the policy changes introduced since 1997 appear to have stabilised PHI coverage at around 45 per cent of the population, there still remain unresolved issues related to the design of - and interaction between - public and private healthcare financing, and to the regulatory tools currently in place in the PHI market. In particular, selection (high-risk individuals are more likely to buy PHI than low-risk groups), which has been a persistent problem in the Australian PHI market. ${ }^{5}$ Between 1997 and 2000, several measures were introduced by the government to increase and stabilise PHI coverage. ${ }^{6}$ Overall these measures have had a positive effect on PHI takeup (e.g. in 2000, 43 per cent of the population was covered by PHI). However, although these measures have been effective in increasing PHI coverage and improved the risk profile within the pool of PHI holders, Brown and Connelly ${ }^{7}$ have shown that the adverse selection problem has not been solved. In particular, they show evidencebased on the age-composition of the insurance pool - of the re-commencement of an adverse selection death spiral in the post-LHC period.

A number of recent theoretical and empirical papers have examined the Australian PHI regulatory framework. Gans and $\mathrm{King}^{8}$ develop a theoretical model and consider the effects of the PHI rebate on insurance outcomes, and find that the rebate can improve welfare by encouraging low-risk individuals to remain in the insurance pool, thereby reducing adverse selection problems. However, they do not consider the effects of the MLS. Palangkaraya and Yong ${ }^{9}$ conduct an econometric analysis of the effect of the PHI rebate, MLS and LHC on PHI take-up rates, and find that the LHC accounted for between 42 per cent and 75 per cent of the increase in take-up rates in 2000. However, they do not develop a theoretical model of these instruments, and do not consider the effects of possible policy changes to take-up rates.

This paper contributes to the existing literature by developing an analytical framework for examining the effects of all three regulatory tools, as well as recently adopted changes. The paper is structured as follows. The next section presents a model of demand for PHI in the presence of a premium subsidy "carrot" and an income

\footnotetext{
${ }^{4}$ All dollar amounts reported in this paper are denominated in Australian dollars.

${ }^{5}$ Butler (2003); Connelly and Brown (2006).

${ }^{6}$ Hall et al. (1999); Butler (2002).

${ }^{7}$ Brown and Connelly (2005).

${ }^{8}$ Gans and King (2003).

${ }^{9}$ Palangkaraya and Yong (2005).
} 
tax "stick". 10 This is followed by a section that extends the model and considers some recently adopted policy changes in Australia. The section "Numerical simulations" models these recently adopted changes in more detail. This is followed by a section on possible policy implications of the modelling results, and then the paper concludes.

\section{The model}

\section{Basic approach}

To illustrate the effects of the PHIR and the MLS, this section develops a diagrammatic model of demand for PHI in the presence of subsidy "carrot" and an income tax "stick". 11

Consider a continuum of consumers, each of whom has discrete demand: they either purchase one unit of PHI, or purchase no PHI at all. Willingness to pay (WTP) for (or valuation of) health insurance is denoted by WTP, and income is denoted by $y$. The price of a health insurance package is $P$. In the absence of any policy intervention, consumers will take up PHI if $W T P>P$.

The policy instruments that are available to the government in this model are as follows. There is an ad valorem price subsidy of $s$ per cent. This is the PHI "carrot". On the other hand, if the consumer does not purchase PHI, they lose a fraction ty of their total income, where $t$ is the tax rate that is levied on the consumer's entire income. This is the income tax "stick".

In the presence of these policy interventions, an individual will purchase PHI only if the (subsidised) net benefits exceed the costs of not purchasing. Hence, under carrot and stick policies, an individual with willingness to pay equal to $W T P$ and income $y$ will purchase insurance if:

$$
W T P-P(1-s) \geqslant-t y
$$

This approach can be extended to examine the effects of policy changes by allowing for tax and subsidy thresholds that vary with income. Consider, for example, an income tax "stick" policy that only taxes individuals above a certain level of income, which is how the MLS works in practice. Assume that a tax rate of $t$ is imposed on individuals whose income is above a certain income threshold $y$ who do not purchase PHI. Thus, the MLS tax rate is:

$$
t(y)= \begin{cases}t & \text { if } y \geqslant \underline{y} \\ 0 & \text { if } y<\underline{y}\end{cases}
$$

\footnotetext{
${ }^{10}$ The "carrot" and "stick" terminology is due to Palangkaraya and Yong (2005).

${ }^{11}$ The model is also used in Robson et al. (2011). A more general mathematical version of the model is developed in Robson and Paolucci (2012).
} 
The individual will now purchase PHI if:

$$
W T P-P(1-s) \geqslant-t(y) y
$$

A tiered system of surcharges can be modelled in a similar way. If there are $n$ tiers running from $j$ to $n$, with thresholds $y_{1}, y_{2}, \ldots, y_{n}$ and rates $t_{1}<t_{2}<\cdots<t_{n}$, then the MLS rate for a particular individual is:

$$
t(y)= \begin{cases}t_{j} & \text { if } \underline{y}_{j+1}>y \geqslant \underline{y}_{j+1} \\ 0 & \text { if } y<\underline{y}_{1}\end{cases}
$$

It is also possible that the PHI rebate may be means-tested, with lower subsidy rates for higher incomes. If the rebate tiers are aligned with the MLS tiers, then the rebate function is:

$$
s(y)= \begin{cases}s_{j} & \text { if } \underline{y}_{j+1}>y \geqslant \underline{y}_{j} \\ s_{0} & \text { if } y<\underline{y}_{j}\end{cases}
$$

where $s_{0}>s_{1}>\ldots>s_{n}$. In this case, the consumer would purchase PHI if:

$$
W T P-P[1-s(y)] \geqslant-t(y) y
$$

\section{Diagrammatic analysis}

The simple approach outlined above can be used to develop a diagrammatic model to analyse the effects of a range of policy changes.

One of the most important implications of the MLS is the effect that it can have on the responsiveness of demand to premium changes for certain consumers. In particular, for consumers who purchase the minimum PHI package in order to avoid paying the MLS, an increase in PHI premiums may have no effect on their demand for PHI, even though such a price change ordinarily (i.e. in the absence of the MLS) would have an effect. In other words, these consumers will likely have a price elasticity of demand of zero. Note that the premium increase certainly makes the consumer worse off. However, the utility loss that the individual experiences as a result of the premium increase is not sufficiently high to induce them to purchase less or no insurance and incur the MLS (see Figure 2).

The result holds more generally in a model with many consumers. This is shown in Figure 3. In this figure we plot income on the horizontal axis and net willingness to pay (that is, including the effects of taxes and subsidies) on the vertical axis. The figure assumes, without loss of generality, that $W T P<P$, so that in the absence of policy interventions, no consumers would purchase PHI.

In Figure 3 we assume that there is a single threshold at the income level $y_{1}$, and a single tax rate of $t$ that the individual faces if PHI is not purchased by individuals 


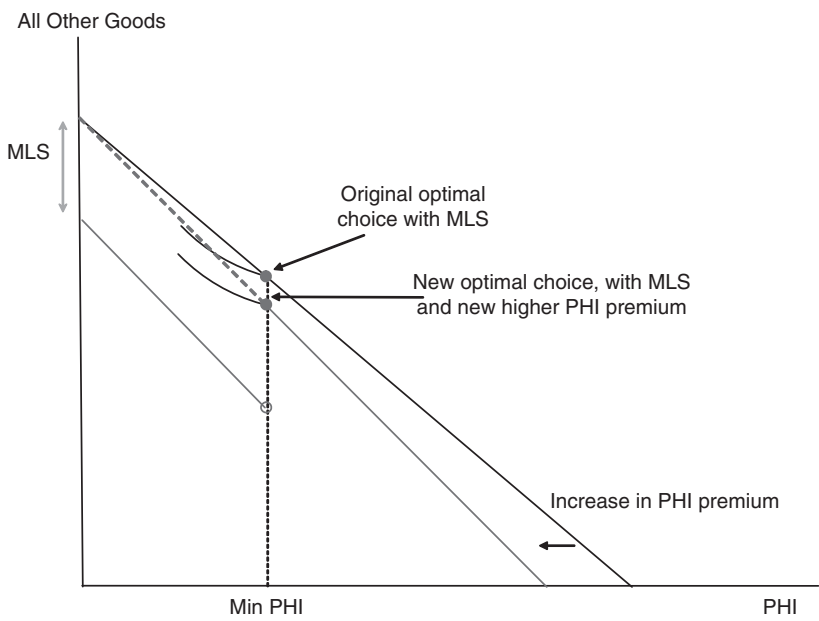

Figure 2. Zero price responsiveness under the Medicare Levy Surcharge: an increase in PHI premiums has no effect on PHI demand.

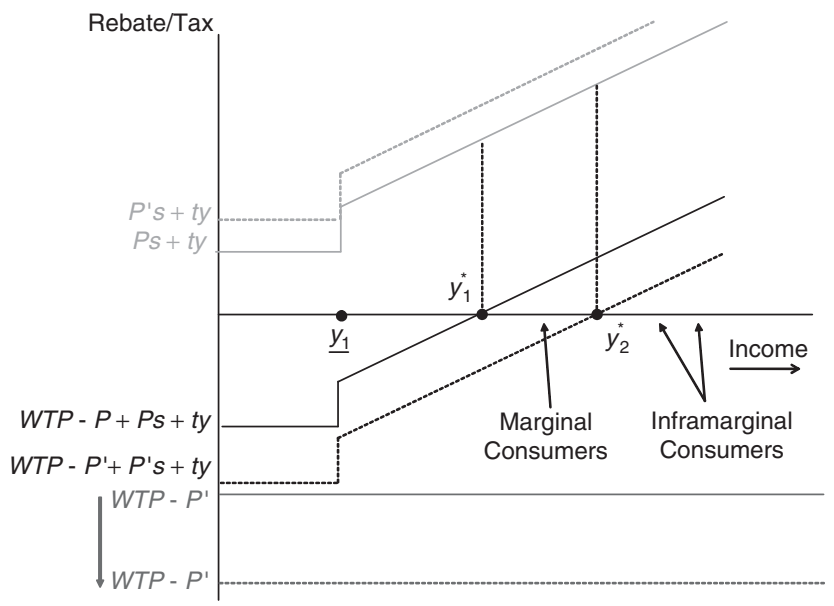

Figure 3. The effect of a higher PHI premium on PHI take-up.

exceeding this income level. Finally, there is a subsidy of $s$, which we assume in the diagram is not means-tested. This gives us the kinked line denoted by $W T P-P+P s+t y$. For all points on this line below the horizontal axis, we have $W T P-P+P s+t y<0$, and so consumers in this range do not purchase PHI. For all points on this line above the horizontal axis, we have $W T P-P+P s+t y>0$, and so consumers in this range do purchase insurance. The cut-off point, $y_{1}^{*}$, is the point where the line crosses the horizontal axis. Thus PHI take-up is measured by looking at all individuals on income levels that lie to the right of $y_{1}^{*}$. 


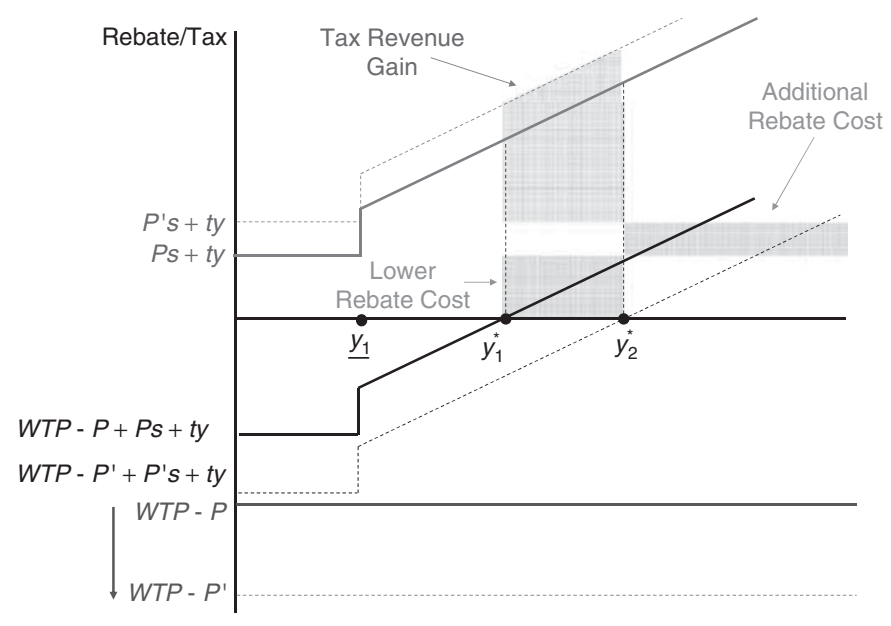

Figure 4. The effect of a higher PHI premium on MLS revenue and PHI rebate expenditure.

Now suppose that health insurance premiums increase from $P$ to $P^{\prime}$. Because the PHI rebate is an ad valorem subsidy, the entire willingness to pay net of financial incentives curve shifts downwards by an amount $\left(P^{\prime}-P\right)(1-s)$, which is the amount of increase in the premium, which is borne by consumers. The result is that PHI take-up falls, but only for marginal consumers, between $y_{1}^{*}$ and $y_{2}^{*}$. Those consumers to the right of $y_{2}^{*}$ still purchase PHI.

The key point is that for higher MLS rates, this effect is muted. In other words, the steeper the net willingness to pay line becomes, for a given vertical shift in the line brought about by a premium increase, the horizontal distance between $y_{1}^{*}$ and $y_{2}^{*}$ is smaller, and take-up falls by less than it otherwise would in response to the price change. In other words, the higher the MLS tax rate, the lower the market price elasticity of demand.

The model can also be used to examine the budgetary consequences of higher PHI premiums. This is illustrated in Figure 4. To the extent that an increase in the PHI premium reduces PHI demand for those who are just on the margin of avoiding paying the MLS, it will unambiguously increase tax revenue from the MLS. However, in the presence of an ad valorem subsidy, an increase in PHI premiums may increase or reduce the overall amount that is spent by the government on the PHI rebate. For higher MLS rates, demand becomes less elastic, and for a given price change the budgetary costs rises. This increase in subsidy expenditure could easily outweigh any increase in tax revenue.

\section{Extending the basic model: Changes to thresholds, rates and means-testing the PHIR}

The model examined in the previous section can be used to analyse the effects on PHI take-up of some recently adopted policy changes in Australia. Prior to 2008 the PHI rebate consisted of a single rate for individuals aged less than 65, and the MLS also consisted of a single rate. Since then, the Australian Government has made several 
significant policy changes that have altered the PHI rebate and the MLS. In its 2009 Budget the Australian Government proposed additional changes to the MLS and the PHI rebate. These changes were part of the Fairer Private Health Insurance Incentives (FPHII) Bill 2009, which passed the House of Representatives but was ultimately defeated in the Senate on 9 September 2009. Instead of the MLS applying at a single rate for individuals and couples and families regardless of income, as of July 12010 the FPHII Bill proposed that there be three new "Private Health Insurance Incentive Tiers". Existing arrangements would remain unchanged for singles with income of less than $\$ 75,000$ per annum and families with incomes of less than $\$ 150,000$ per annum. The three proposed new tiers were as follows:

- Tier 1: singles with income of more than $\$ 75,000$ but less than $\$ 90,000$ (double amounts for families). The PHI rebate would be 20 per cent, increasing to 25 per cent at 65 years of age, and to 30 per cent at 70 years. The MLS would remain at 1 per cent.

- Tier 2: singles with income between $\$ 90,001$ and $\$ 120,000$ (double amounts for families). The PHI rebate will be 10 per cent, increasing to 15 per cent at 65 years of age, and to 20 per cent at 70 years. The MLS will be increased to 1.25 per cent.

- Tier 3: singles with income of more than $\$ 120,000$ (double amounts for families). No PHI rebate will be provided. The MLS will be increased to 1.5 per cent.

The Government revived and reintroduced the proposed changes into the House of Representatives on 7 July 2011 with a slightly modified system of tiers. The Bills passed the Australian Parliament in February 2012.

Figures 5 and 6 illustrate the impact that the originally announced changes would have had on individuals on different income levels. First, Figure 5 plots the annual dollar value of the PHI rebate (assuming an annual premium of $\$ 1,000$ ) and the MLS for a single person under the age of 65 under the tiered scheme.

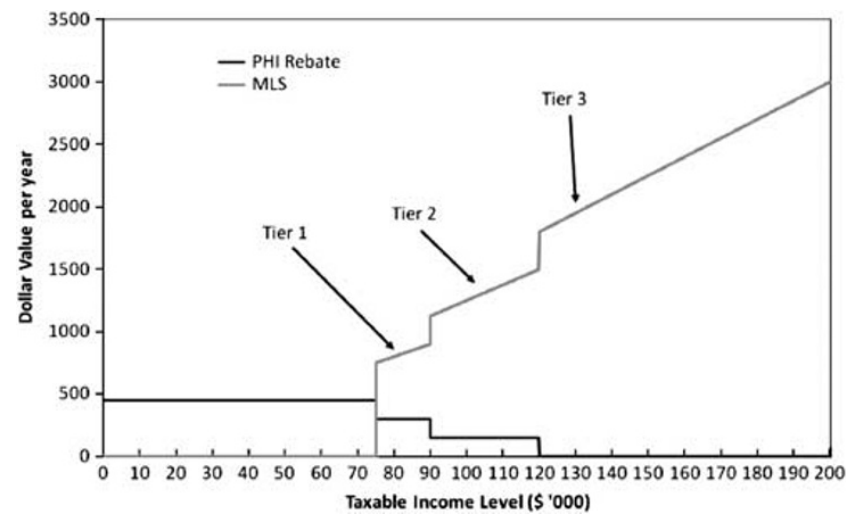

Figure 5. Annual dollar values of PHI rebate and the MLS, 2009 changes (assumes PHI premium of $\$ 1,000)$. 


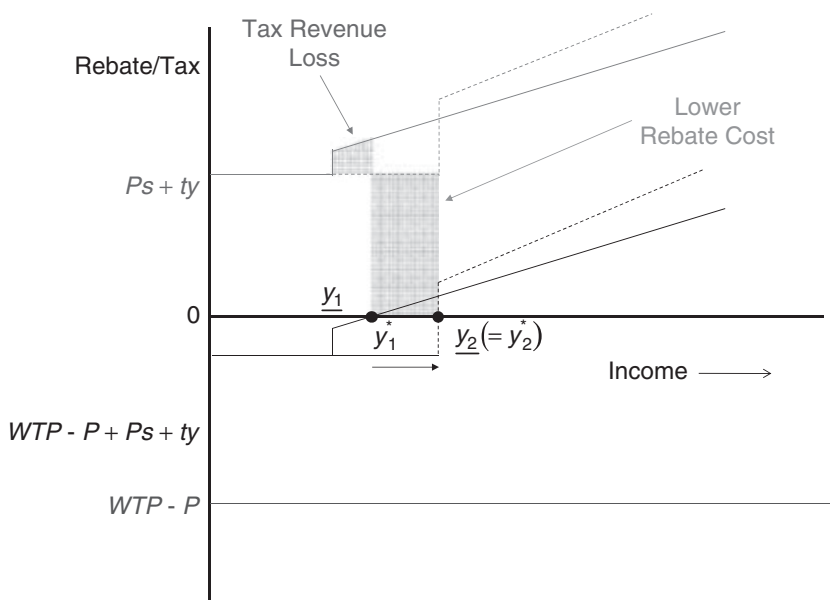

Figure 6. An increase in the MLS rate and threshold, which reduces PHI take-up.

The model developed in the second section can be used to show that the effects on PHI take-up of a combined increase in the MLS threshold and MLS rate will, in theory be ambiguous.

This case where this policy change leads to a reduction in PHI demand is illustrated in Figure 6. The increase in the MLS threshold shifts the entire willingness to pay net of financial incentives curve to the right. The new higher MLS rate increases the slope of the curve, but the position of the new threshold relative to the willingness to pay means that no consumers actually pay the MLS. The government loses the tax revenue it was collecting from the MLS, but because PHI take-up rate is lower, the rebate costs fall.

\section{The effect of means-testing the PHI rebate}

The other major recent policy change, means-testing the PHI rebate, is also straightforward to analyse within our framework. To isolate the effects of this policy, we examine the effect of establishing a threshold beyond which the PHI rebate is reduced.

This case where means-testing the PHI rebate reduces PHI take-up is illustrated in Figure 7. The PHI rebate is reduced for individuals with income above the level indicated, and the reduction induces some individuals to drop their PHI cover. As a result, PHI take-up falls to $y_{2}^{*}$, the budgetary cost of the PHI rebate falls and MLS revenue increases.

Overall, the analysis above suggests that the Australian Government's recent policy changes are likely to reduce PHI take-up, although the size of the effect is ultimately an empirical question. To consider the possible effects of the recently adopted changes in more detail, we ran simulations of the model in the second section, incorporating differing income levels, willingness- to-pay assumptions, tax thresholds, tax rates and subsidies. 


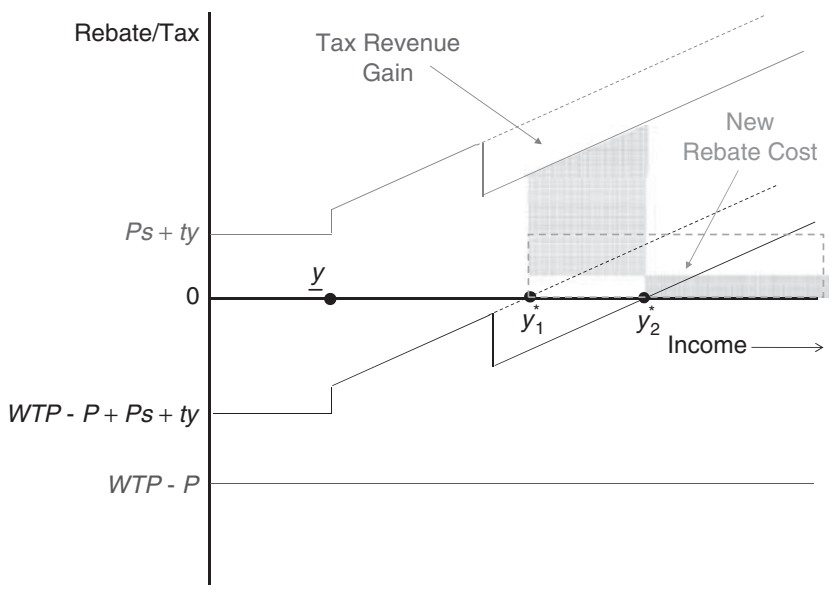

Figure 7. The effect of a reduction in the PHI rebate for incomes above a certain threshold.

\section{Numerical simulations}

This section undertakes a sensitivity analysis of several scenarios using Monte Carlo simulations. Monte Carlo analysis entails forming probability distributions for each variable known to have a significant impact on the overall result and for which there is a high degree of uncertainty about the magnitude of the variable (such as income and willingness to pay for PHI and the empirical relationship between the two). These distributions are then repeatedly sampled (e.g. 1,000 times) and the expected effects are then calculated for each sampling round. These results can then be used to generate probabilistic statements about the overall expected effects of changes to the MLS and the PHI rebate.

\section{Scenarios and modelling approach}

In our simulations we consider the following sets of scenarios:

- Scenario A: Baseline of no policy intervention

- Scenario B: PHI rebate and MLS before the recent (2008 and 2009) changes

- Scenario C: PHI rebate and MLS incorporating the changes in thresholds and tiers that were proposed in the FPHII (2009) Bill

- Scenario D: PHI more tightly means-tested, with MLS rates and thresholds increased

- Scenario E: PHI rebate is completely removed, and MLS rates and thresholds increased

In each simulation we make the following assumptions. We assume that income levels and health risks (willingness to pay) are jointly log-normally distributed with a correlation coefficient of $\rho$, where $|\rho|<1$. The simulations are standard Monte-Carlo simulations and proceed as follows:

1. Draw a sample of 1,000 (valuation, income pairs) from a jointly log-normal distribution with assumed correlation coefficient $\rho$. 
2. Assume a PHI price $p$, and sort individuals into whether $W T P_{i} \geqslant p$ or not.

3. Assume PHI rebate, and MLS structure, and investigate changes in aggregate PHI demand for consumers with $W T P_{i}<p$.

4. Examine whether MLS is paid by each of these 1000 individuals or not, and if so, what is the average MLS rate paid, conditional on PHI not being taken up.

5. Repeat steps (1)-(4) 1,000 times, using a new set of draws of 1,000 (valuation, income pairs) from the same distribution.

6. Collect data from these simulations and examine probability distribution of outputs (take-up, MLS payers, MLS paid, rebate expenditure, etc.).

7. Repeat steps (1)-(6) for each policy scenario and compare distributions of outputs.

\section{Simulation results}

This section sets out the assumptions of the simulations in more detail, and presents and discusses the results.

\section{Scenario A}

Scenario A is the baseline scenario, and assumes that the PHI rebate is zero and that there is no MLS payable at any income level. To parameterize the model, we make a number of assumptions based on empirical observations. First, we obtained an estimate of income distribution from Australian Taxation Office (ATO) data, which publishes data on the distribution of taxable income by income percentile. At the time of writing, 2006-2007 data was the most recent year for which this data was available. The histogram of the data (shown in Figure 8) suggests that taxable income in Australia is log-normally distributed - a range of standard formal tests of the (natural logarithm) of the raw data fail to reject the null hypothesis of normality. The estimated mean of the logarithm of the raw taxable income data is 10.66 , with an estimated standard deviation of 0.65 . To better approximate annual income at the time of writing, the simulations assume income has a lognormal distribution with a slightly higher mean of 10.8 , with a standard deviation of 0.65 . This results in average annual income of $\$ 60,550$, which is just slightly lower than observed estimates of average weekly earnings as at May 2009.

Insurance premiums in Australia vary by State. Table 1 provides a summary of publicly available data on PHI package prices for young single hospital cover across all Australian states in September 2009. The data in Table 1 shows that the average annual premium is around $\$ 1,000$.

Our assumptions on willingness to pay (which cannot be observed) are deliberately designed to be consistent with the premium data in Table 1, as well the data on take-up rates in Figure 1, which suggests that in the absence of policy measures, overall PHI take-up would be around 30 per cent.

For willingness to pay for PHI, we assume a log-normal distribution, with log WTP having a mean of 6 and standard deviation of 2. This gives WTP a reasonable median of $\$ 403$, and a mean of $\$ 2,980$. For all simulations we assume that the PHI premium is $\$ 1,000$, which, as discussed above, approximates the average annual premium in 2009. 


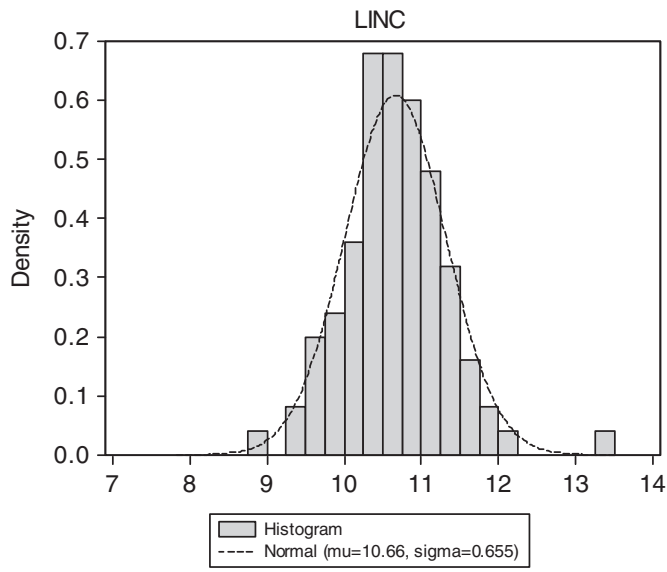

Figure 8. Histogram of (natural logarithm) of taxable income data, 2006-2007.

Table 1 Summary statistics of annual premiums for young single hospital cover as at September 2009

\begin{tabular}{lccccrr}
\hline & $N S W$ & VIC & QLD & \multicolumn{1}{c}{$S A$} & \multicolumn{1}{c}{$W A$} & $T A S$ \\
\hline Mean & $\$ 922.66$ & $\$ 1,039.80$ & $\$ 1,015.08$ & $\$ 989.08$ & $\$ 908.75$ & $\$ 1,007.84$ \\
Median & $\$ 921.30$ & $\$ 1,045.08$ & $\$ 1,018.80$ & $\$ 1,000.80$ & $\$ 918.00$ & $\$ 1,020.60$ \\
Max & $\$ 1,388.40$ & $\$ 1,587.00$ & $\$ 1,507.80$ & $\$ 1,511.40$ & $\$ 1,355.88$ & $\$ 1,551.00$ \\
Min & $\$ 511.20$ & $\$ 527.40$ & $\$ 571.20$ & $\$ 580.80$ & $\$ 416.40$ & $\$ 538.80$ \\
Std. dev. & $\$ 216.55$ & $\$ 238.52$ & $\$ 239.34$ & $\$ 232.29$ & $\$ 236.19$ & $\$ 230.94$ \\
Obs & 62 & 80 & 68 & 59 & 123 & 59 \\
\hline
\end{tabular}

Source: Cannex ${ }^{12}$; authors' own calculations.

Finally, we assume that the correlation between the log of income and the log of willingness to pay is 0.5 . This means that higher incomes will tend be associated with higher willingness to pay, although the relationship between the two will not be perfect. The simulation results for Scenario A are summarised in Table 2, and show that in the absence of any policy measures, these assumptions result in a take-up rate of just over 30 per cent, which is consistent with the data in Figure 1.

In this baseline scenario, the average PHI take-up rate across the simulations is 32.5 per cent, with those on higher incomes tending to take up PHI. This computed take-up rate in the absence of the MLS, the PHIR and the LHC is not unreasonable. For example, Frech et al. ${ }^{13}$ conservatively estimate that in the absence of the LHC and other interventions introduced in the late 1990s, the PHI take-up rate would

\footnotetext{
${ }^{12}$ Cannex (2009).

${ }^{13}$ Frech et al. (2003).
} 
Table 2 Simulation results for Scenario A

\begin{tabular}{lllllll}
\hline Take-up & \multicolumn{2}{c}{ Purchasers } & & \multicolumn{2}{c}{ Non-purchasers } & Elasticity \\
\cline { 2 - 3 } & Average income & Average WTP & & Average income & Average WTP & \\
\hline $32.53 \%$ & $\$ 83,540.16$ & $\$ 8,583.12$ & & $\$ 23,017.48$ & $\$ 269.82$ & -0.52 \\
\hline
\end{tabular}

Table 3 Assumed rates and thresholds for Scenario B

\begin{tabular}{lcccc}
\hline Policy variables & \multicolumn{3}{c}{ Tier } \\
\cline { 2 - 5 } & 0 & 1 & 2 & 3 \\
\hline MLS thresholds & 0 & $\$ 50,000$ & $\$ 50,000$ & $\$ 50,000$ \\
MLS rates $(\%)$ & 0 & 1 & 1 & 1 \\
PHI rebate $(\%)$ & 30 & 30 & 30 & 30 \\
\hline
\end{tabular}

have declined to 25 per cent by late 2001. If the LHC and other policy interventions had not occurred and the downward trend in PHI take-up had continued, it is not implausible that PHI take-up would have declined to very low rates.

In the baseline scenario, the average income of those who purchase PHI is $\$ 83,540$, while the average income of those who do not purchase PHI is $\$ 23,018$. The median willingness to pay for those who choose purchase PHI is $\$ 2,980$ (the average is $\$ 8,583$ ), while the median WTP for those who do not purchase is $\$ 403$ (average WTP for this group is $\$ 259$ ).

These outputs are sensitive to the initial price that is assumed. An increase in premiums by 10 per cent, to $\$ 1100$, for example, reduces the take-up rate to 30.9 per cent. This gives us an aggregate (point) price elasticity of demand of -0.518 , which is not unreasonable. Butler, ${ }^{14}$ for example, estimates an own price elasticity of demand of -0.5 for hospital insurance.

\section{Scenario $B$}

Scenario B assumes that the MLS thresholds and rates and the PHI rebate are set at pre-2008 levels. We again assume the same parameters as in Scenario A (Table 3).

The simulation results are summarised in Table 4. The results show that the main effect of the MLS and the PHI rebate is to induce lower income earners into PHI. Under our assumptions the combined effect of the carrot and stick is to increase the take-up rate to an average of 57.4 per cent across the simulations.

The overall effect of this policy combination is for lower income earners to get pushed into PHI. The average income of those who purchase PHI is now $\$ 81,446$, while the average income of those who do not purchase PHI is $\$ 20,885$. The average

\footnotetext{
${ }^{14}$ Butler (1999).
} 
Table 4 Results of simulation for Scenario B

\begin{tabular}{lllllll}
\hline Take-up & \multicolumn{2}{c}{ Purchasers } & & \multicolumn{2}{c}{ Non-purchasers } & Elasticity \\
\cline { 2 - 3 } & Average income & Average WTP & & Average income & Average WTP & \\
\hline $57.38 \%$ & $\$ 81,446.55$ & $\$ 5,053.63$ & & $\$ 20,885.46$ & $\$ 165.56$ & -0.48 \\
\hline
\end{tabular}

Table 5 Assumed rates and thresholds for Scenario C

\begin{tabular}{lcccc}
\hline Policy variables & \multicolumn{3}{c}{ Tier } \\
\cline { 2 - 5 } & 0 & 1 & 2 & 3 \\
\hline MLS thresholds & 0 & $\$ 75,000$ & $\$ 90,000$ & $\$ 120,000$ \\
MLS rates (\%) & 0 & 1.00 & 1.25 & 1.50 \\
PHI rebate (\%) & 30 & 20 & 10 & 0 \\
\hline
\end{tabular}

willingness to pay for those who choose purchase PHI is now $\$ 5,053$, while the average WTP for those who do not purchase is $\$ 165$.

The price elasticity of demand is lower in this scenario than in the baseline. An increase in the PHI premium to $\$ 1,100$ results in an average take-up rate of 54.6 per cent, giving us a price elasticity of demand of -0.48 . As take-up rises and we move down along a given demand curve, it is reasonable to expect that the price elasticity of demand would fall. Thus, the observed fall in the (absolute value of) the own-price elasticity of demand here does not necessarily provide any indication of the effect of the MLS on elasticity of demand.

\section{Scenario $C$}

Scenario $\mathrm{C}$ assumes that the MLS thresholds and rates and the PHI rebate are set at the levels contained in the FPHII Bill (2009). We again assume the same parameters as in Scenario A (Table 5).

The simulation results are summarised in Table 6 . The results show that in aggregate terms, the main effect of introducing tiers into the MLS and the PHI rebate is to lower PHI take-up to an average of 48 per cent, although take-up effect could be as low as 44 per cent or as high as 51 per cent after this change.

On average, the overall effect of this policy combination is that once again some lower income earners are induced to drop PHI coverage. The average income of those who purchase PHI is now $\$ 85,100$, while the average income of those who do not purchase $\mathrm{PHI}$ is $\$ 24,550$. The average willingness to pay for those who choose purchase PHI is now \$5,988), while the average WTP for those who do not purchase is \$192.

Take-up in this scenario is lower, but the own-price elasticity of demand is also lower in this scenario than in scenario B. An increase in the PHI premium to $\$ 1,100$ results in an average take-up rate of 46.3 per cent, giving an own-price elasticity of 
Table 6 Results of simulation for Scenario C

\begin{tabular}{lllllll}
\hline Take-up & \multicolumn{2}{c}{ Purchasers } & & \multicolumn{2}{c}{ Non-purchasers } & Elasticity \\
\cline { 2 - 3 } & Average income & Average WTP & & Average income & Average WTP & \\
\hline $48.04 \%$ & $\$ 85,100.50$ & $\$ 5,989.00$ & & $\$ 24,550.70$ & $\$ 192.34$ & -0.37 \\
\hline
\end{tabular}

Table 7 Assumed rates and thresholds for Scenario D

\begin{tabular}{lcccc}
\hline Policy variables & \multicolumn{3}{c}{ Tier } \\
\cline { 2 - 5 } & 0 & 1 & 2 & 3 \\
\hline MLS thresholds & 0 & $\$ 80,000$ & $\$ 100,000$ & $\$ 150,000$ \\
MLS rates $(\%)$ & 0 & 1.25 & 1.50 & 1.75 \\
PHI rebate $(\%)$ & 30 & 10 & 0 & 0 \\
\hline
\end{tabular}

demand -0.37 per cent. As take-up falls and we move up along a given demand curve, we would ordinarily expect elasticity of demand to rise. The observed fall in the (absolute value of) the own-price elasticity of demand here provides support for the theoretical results derived earlier - that an increase in MLS rates reduces the price elasticity of demand for PHI.

\section{Scenario D}

Scenario D assumes that the MLS thresholds and rates and the PHI rebate are even more tightly means-tested than they are in the FPHII Bill (2009). We again assume the same parameters as in Scenario A. The assumed rates and thresholds are given in Table 7.

The simulation results are summarised in Table 8 . The results show that once again, in aggregate terms, the main effect of increasing the MLS rates and thresholds is to lower PHI take-up, this time to an average rate of 46.6 per cent, although take-up could be as low as 43 per cent or as high as 50 per cent after this change.

On average, the overall effect of this policy combination is once again that some lower income earners are induced to drop PHI coverage. The average income of those who purchase PHI is now $\$ 85,313$, while the average income of those who do not purchase PHI is $\$ 24,771$. The average willingness to pay for those who choose purchase PHI is now $\$ 6179$, while the average WTP for those who do not purchase is $\$ 194$. Once again, elasticity of demand falls, this time to an average of -0.29 .

\section{Scenario E}

Scenario E contains the same assumptions around the MLS as in Scenario D, but assumes that the PHI rebate is completely removed. We again assume the same parameters as in Scenario A (Table 9). 
Table 8 Summary of results of simulation for Scenario D

\begin{tabular}{lllllll}
\hline Take-up & \multicolumn{2}{c}{ Purchasers } & & \multicolumn{2}{c}{ Non-purchasers } & Elasticity \\
\cline { 2 - 3 } & Average income & Average WTP & & Average income & Average WTP & \\
\hline $46.64 \%$ & $\$ 85,313.17$ & $\$ 6,179.91$ & & $\$ 24,771.30$ & $\$ 194.34$ & -0.29 \\
\hline
\end{tabular}

Table 9 Assumed rates and thresholds for Scenario E

\begin{tabular}{lcccc}
\hline Policy variables & \multicolumn{3}{c}{ Tier } \\
\cline { 2 - 5 } & 0 & 1 & 2 & 3 \\
\hline MLS thresholds & 0 & $\$ 80,000$ & $\$ 100,000$ & $\$ 150,000$ \\
MLS rates (\%) & 0 & 1.25 & 1.50 & 1.75 \\
PHI rebate (\%) & 0 & 0 & 0 & 0 \\
\hline
\end{tabular}

Table 10 Results of simulation for Scenario E

\begin{tabular}{lllllll}
\hline Take-up & \multicolumn{2}{c}{ Purchasers } & & \multicolumn{2}{c}{ Non-purchasers } & Elasticity \\
\cline { 2 - 3 } & Average income & Average WTP & & Average income & Average WTP & \\
\hline $41.69 \%$ & $\$ 89,884.98$ & $\$ 6,809.29$ & & $\$ 29,339.67$ & $\$ 249.15$ & -0.36 \\
\hline
\end{tabular}

The simulation results are shown in Table 10. The results show that on average across the simulations, the effect of completely abolishing the PHI rebate in these circumstances is to reduce PHI take-up to 41.7 per cent on average across the simulations.

On average, the overall effect of this policy combination is once again that lower income earners are induced to drop PHI coverage. The average income of those who purchase $\mathrm{PHI}$ is now $\$ 89,885$, while the average income of those who do not purchase $\mathrm{PHI}$ is $\$ 29,340$. The average willingness to pay for those who choose purchase $\mathrm{PHI}$ is now $\$ 6,809$, while the average WTP for those who do not purchase is $\$ 294$. Demand is more elastic than in scenario $D$, but this happens because the effect of a 10 per cent increase in price is now fully felt by all consumers, whereas in the other scenarios the presence of the PHI rebate reduced the effect of a given premium change by the amount of the PHI rebate for those consumers who benefited from it.

\section{Policy implications}

According to the simulations for each scenario, overall PHI take-up declines relative to the baseline scenario (i.e. without any policy change), with PHI demand increasingly concentrated among high-income consumers. The price elasticity of 
PHI demand also falls as the proportion of MLS avoiders within the PHI pool is increased as a consequence of ever-high MLS rates.

If both of these effects were to occur, the consequences for the PHI industry and for the government's budgetary position are potentially substantial. ${ }^{15}$ The immediate or first round effect of a PHI pool with high-income consumers is that low-income individuals, who have been reducing their PHI cover, will increasingly rely on the public (hospital) system. This would further strain the public system by increasing the pressure on constrained public finances, and waiting times for access to public hospitals, particularly for low-income individuals potentially exacerbating the consequences of a two-tier system in terms of efficiency and equity.

As noted in the introduction, price increases above inflation require Ministerial approval. Hence, all else being equal, a reduction in the price elasticity of demand may have little effect on observed price increases. However, not all else is equal: a lower price elasticity of demand means that any given increase in prices will produce a greater increase in revenue for insurance companies than was previously the case. Hence, at the margin, there may be a greater incentive for health insurance companies to devote more resources to lobbying for price increases in excess of inflation, so as to secure these greater increases in revenue. By the same token, consumers will have more to lose from premium increases and may increase pressure against price increases. As a result, it is not unreasonable to expect public pressure both for and against annual price increases to become more intense, and for price increases to become more controversial.

In addition, a lower elasticity of PHI demand could lead to premium inflation, which would reduce demand slightly, but increase public PHI-rebate expenditures. A lower market elasticity may also induce upstream input suppliers (such as specialists, diagnostic providers and private hospitals) to increase their own prices, in an attempt to capture any additional profits that may be made available as a result of higher premiums. Finally, low willingness to pay for PHI may be a reflection of low risks. If low-income, low-risk consumers drop their PHI cover as MLS thresholds rise (as our simulation results tend to suggest), then the overall riskiness of the remaining pool increases, aggravating adverse selection and driving up providers' costs and the pressure on premiums.

There are also some important implications of our analysis for a possible transition to a competitive social insurance model. A proposal for such a transition has been made in the final report of the National Health and Hospital Reform Commission ${ }^{16}$ and was labelled "Medicare Select". ${ }^{17}$ The essence of that model is that insurers ultimately act as full risk bearers on behalf of their members, and take responsibility for the purchasing of health-care services. Insurance coverage in this approach is universally mandatory, with each consumer obtaining insurance from a single fund

15 Robson et al. (2011).

16 NHHRC (2009).

17 A description and discussion of "Medicare Select" can be found in Hall (2010). The proposal for the introduction of competitive social health insurance in Australia by the NHHRC was inspired by the arguments of Scotton $(1990,1995)$ for "Transferable Medicare entitlements", Stoelwinder and Paolucci (2009) for "Medicare Choice", and Paolucci et al. (2011) for "Medicare/PHI Choice". 
(as against the duplicative approach currently in operation, where privately insured individuals are covered both by Medicare and by PHI). As well as harnessing the disciplines of competitive markets, this approach has the benefit that it extends to all consumers (and notably those on low incomes) the choice that is now only available to those with PHI and also eliminates the inefficiencies associated with duplicative cover. $^{18}$

However, for this model to work insurers must be sufficiently robust to act as the pillars of the system. To that extent, an effective and efficient PHI industry is required if government is to have the option of moving to competitive social insurance over time. Moreover, as that transition is made, the responsibilities being placed on the PHI funds will rise, requiring them to have both the financial strength and the depth of expertise to discharge those responsibilities. In that perspective, recently adopted policy changes that potentially leave PHI funds with a substantially smaller customer base, but also one that is increasingly not by choice but by compulsion, raises concerns in terms of optimal pathways towards the implementation of competitive social health insurance. As the MLS is used to induce consumers into PHI, there is a risk for PHI funds to become less, rather than more, responsive to their customers.

These concerns are additional to the numerous inefficiencies noted earlier, whereby consumers incur potentially significant welfare losses, as many are coerced into purchasing a service that they value less than its cost. Suppliers-both of PHI and of upstream health services - will face less elastic demand, and hence will have the scope and incentive to increase charges. This may indirectly increase costs in the public system as well, to the extent to which that system competes with the private system for inputs that can now extract higher prices when they shift into that private system. Finally, any reductions in PHI cover could have effects on the demands placed on the public system, though the extent of those added demands will depend on the degree to which costs in the two systems are in fact substitutes.

\section{Conclusion}

This paper has used a model of the demand for PHI in Australia in the presence of policy interventions and used a numerical simulation of the model to analyse possible effects of recently adopted policy changes.

An important strength of our approach is that it incorporates consumer heterogeneity in income and risk (willingness to pay) profiles, and our simulations allowed for possible dependence (i.e. correlations) between these variables. The results suggest that increases in tax rates will reduce the price elasticity of demand for PHI. Simulations of the model, using a specific functional form for the joint distribution of income and willingness to pay, suggest that recently adopted policy changes in Australia could reduce take-up rates and further reduce price responsiveness in a system that, due to the LHC policy, already encourages consumers to take up PHI earlier than they

\footnotetext{
${ }^{18}$ Paolucci et al. (2011).
} 
otherwise might have, and to remain "locked in" to insurance coverage even where its benefits may significantly exceed costs.

\section{References}

Brown III, H.S. and Connelly, L.B. (2005) 'Lifetime cover in private insurance markets', International Journal of Healthcare Finance and Economics 5(1): 75-88.

Butler, J.R.G. (1999) 'Health expenditure', in G.H. Mooney and R.B. Scotton (eds.) Economics and Australian Health Policy, Sydney: Allen \& Unwin, pp. 40-71.

Butler, J.R.G. (2002) 'Policy change and private health insurance: Did the cheapest policy do the trick?' Australian Health Review 25(6): 33-41.

Butler, J.R.G. (2003) 'Adverse selection, genetic testing and life insurance-Lessons from health insurance in Australia', Agenda 10(1): 73-89.

Butler, J.R.G. (2007) Adverse selection in Australian private health insurance: Recent trends, presentation to the ACERH Research Forum on Healthcare Financing and Private Health Insurance: International Experience and Recent Australian Trends, 24 September, Canberra from http://www.acerh.edu.au/ research_forums.php.

Cannex (2009) 'Compare private health insurance - Comparison of star ratings', from http://www.canstar com.au/health-insurance/, accessed September 2009.

Connelly, L.B. and Brown III, H.S. (2006) 'Lifetime subsidies in Australian private health insurance markets with community rating', The Geneva Papers on Risk and Insurance - Issues and Practice 31(4): 705-719.

Frech, T., Hopkins, S. and Macdonald, G. (2003) 'The Australian health insurance boom: Was it subsidies or liberalised regulation?' Economic Papers 22(1): 58-64.

Gans, J. and King, S. (2003) 'Anti-insurance: Analysing the health insurance system in Australia', Economic Record 79(247): 473-486.

Hall, J. (2010) 'Medicare select: A bold reform? Policy forum: Reforming the health system', The Australian Economic Review 43(1): 63-70.

Hall, J., De Abreu Lourenco, R. and Viney, R. (1999) 'Carrots and sticks-The fall and fall of private health insurance in Australia', (editorial) Health Economics 8(8): 653-660.

NHHRC (2009) A Healthier Future For All Australians, Final Report (June), Canberra.

OECD (2004) 'Private health insurance in OECD Countries-The OECD health project', from http:// www.oecd.org/health/privatehealthinsuranceinoecdcountries-theoecdhealthproject.htm.

Palangkaraya, A. and Yong, J. (2005) 'Effects of recent carrot and stick policy initiatives on private health insurance coverage in Australia', Economic Record 81(254): 262-272.

Paolucci, F. (2011) Healthcare Financing and Insurance: Options for Design, Developments in Health Economics and Public Policy No. 10, 1st edn, The Netherlands: Springer.

Paolucci, F., Butler, J.R.G. and Van de Ven, W.P.M.M. (2011) 'Removing duplication in public/private health insurance in Australia: Opting out with risk-adjusted subsidies?' Agenda 18(2): 49-70.

Paolucci, F., Den Exter, A. and Van de Ven, W.P.M.M. (2006) 'Solidarity in competitive health insurance markets: Analysing the relevant EC legal framework', Health Economics Policy and Law 1(2): 107-126.

Paolucci, F. and Shmueli, A. (2011) 'The introduction of ex ante risk-equalisation in the Australian private health insurance market: A first step', Agenda 18(2): 71-92.

Private Health Insurance Administration Council (2011) 'Per cent of People with Hospital Cover', from http://www.phiac.gov.au/for-industry/industry-statistics/statisticaltrends/.

Robson, A., Ergas, H. and Paolucci, F. (2011) 'The analytics of the Australian Private Health Insurance Rebate and the Medicare Levy Surcharge', Agenda 18(2): 27-47.

Robson, A. and Paolucci, F. (2012) Price carrots and income sticks: A theoretical analysis, unpublished working paper.

Scotton, R.B. (1990) 'Integrating Medicare with private health insurance: The best of both worlds?', in C. Selby Smith (ed.) Economics Health 1989: Proceedings of the Eleventh Australian Conference of Health Economists, Melbourne: Public Sector Management Institute, Monash University.

Scotton, R.B. (1995) 'Managed competition: Issues for Australia', Australian Health Review 18(1): 82-104. 
Stoelwinder, J. and Paolucci, F. (2009) 'Sustaining Medicare through consumer choice of health funds: Lessons from the Netherlands', Medical Journal of Australia 191(1): 30-32.

Van de Ven, W.P.M.M. and Schut, F.T. (2007) 'Risk equalization in an individual health insurance market: The only escape from the trade-off between affordability, efficiency and selection', from http://freshthinking.org/publications/pubs.htm.

\section{About the Authors}

Alex Robson is a senior lecturer in Economics at Griffith University in Brisbane, Australia. He previously held academic appointments at the Australian National University in Canberra and the University of Wollongong, and holds a $\mathrm{PhD}$ in Economics from the University of California, Irvine, U.S. He has published papers in public economics and law and economics, and is the author of the book Law and Markets published in 2012.

Francesco Paolucci is Reader at Northumbria University and Fellow at The Australian National University. He held academic appointments in several academic institutions as (visiting) researcher and lecturer, for example the Institute of Health Economics and Management at the University of Oslo, and at iBMG at the Erasmus University of Rotterdam where he wrote his $\mathrm{PhD}$ thesis. He has published extensively in health policy and economics journals, and recently published a book entitled "Health Care Financing and Insurance: Options for Design". 